\title{
AN ASSESSMENT OF THE ACCURACY OF STRUCTURE-FROM-MOTION (SFM) PHOTOGRAMMETRY FOR 3D TERRAIN MAPPING
}

\author{
Chima Jude Iheaturu, Emmanuel Gbenga Ayodele, Chukwuma John Okolie
}

\begin{abstract}
Summary
Unmanned Aerial Vehicles (UAVs) equipped with photogrammetric or remote sensing instrumentations offer numerous opportunities in mapping and data collection for topographic modelling. An example is an emerging technique known as Structure-from-Motion (SfM) photogrammetry used for the collection of low-cost, high spatial resolution, three-dimensional data. This study utilised the real time kinematic-based point-to-point validation technique and two sets of randomly selected ground control points to assess the capability and geometric accuracy of SfM-technology for three-dimensional (3D) terrain mapping over a small study area to contribute to the knowledge of applicability. The data used was collected in Garscube Sports Complex, Glasgow City Council, Scotland. The study utilised fifteen (15) Ground Control Points (GCPs) coordinated by the Real Time Kinematic Global Navigation Satellite System (RTK GNSS) positioning technique, while a DJI Phantom 3 Professional unmanned aerial vehicle was used to obtain the aerial photos in a single flight to minimise cost. The processing of the photos was done using Pix4Dmapper Pro software version 4.2.27. A point-to-point validation method was used to evaluate the $3 \mathrm{D}$ positional accuracy of the orthophoto and DSM. The results of the validation with ten checkpoints suggest a high level of accuracy and acceptability given a Root Mean Square Error of $20.93 \mathrm{~mm}, 18.48 \mathrm{~mm}$ and $46.05 \mathrm{~mm}$ in the X, Y and Z coordinates respectively. In conclusion, the study has shown that SfM technique can be used to produce highresolution and accurate topographic data for geospatial applications with significant advantages over the traditional methods. However, it is to be noted that the quality of the data captured is dependent on the methodology adopted and should be taken into consideration.
\end{abstract}

\section{Keywords}

SfM photogrammetry $\bullet$ orthophoto $\bullet$ DSM $\bullet$ topography $\bullet$ GNSS

\section{Introduction}

Technological developments in the field of geomatics have been dynamic and fast-paced. Conventional techniques of obtaining topographic data are gradually being replaced by modern technology such as automated photogrammetric and laser systems. This modern technology offers significant advantages over conventional techniques in terms of cost, 
efficiency, and ease of acquisition of topographic data for geospatial applications. An example includes the automated photogrammetric systems deployed on platforms such as Unmanned Aerial Vehicles (UAVs) commonly called drones. Recently, a technique known as Structure-from-Motion (SfM) has been suggested as a valid alternative to traditional photogrammetric methods, Terrestrial Laser Scanning (TLS), and Airborne Laser Scanning (ALS) [Raoult et al. 2017]. SfM photogrammetry is a low-cost image processing technique that allows the construction of accurate three-dimensional geo-located terrain and object models from overlapping successive photographs taken from cameras at various angles with or without ground control points [Westoby et al. 2012 in: Ostwald and Hurtado 2017, Raoult et al. 2017]. This technology has also been described as an emerging technique for collecting low-cost, high spatial resolution, three-dimensional (3D) data for topographic or surface modelling in many fields [Dietrich 2014]. The origins and principles of SfM have already been extensively reviewed elsewhere [e.g. Westoby et al. 2012, Dietrich 2014, Nilosek et al. 2014, Wrozynski et al. 2017] and only a brief explanation is required here. Structure from Motion follows the same basic concept of stereoscopic photogrammetry, in which 3D structures are resolved from a series of overlapping, offset images (Fig. 1). The difference between SfM and conventional photogrammetry is that in the geometry of the scene, the camera position and orientation is solved automatically without the need to specify a priori, a network of ground control points (or targets) which have known 3D positions [Westoby et al. 2012]. Instead, these are solved simultaneously using an iterative bundle adjustment procedure, based on a database of features automatically extracted from a set of multiple overlapping images [Snavely 2008 in: Westoby et al. 2012].

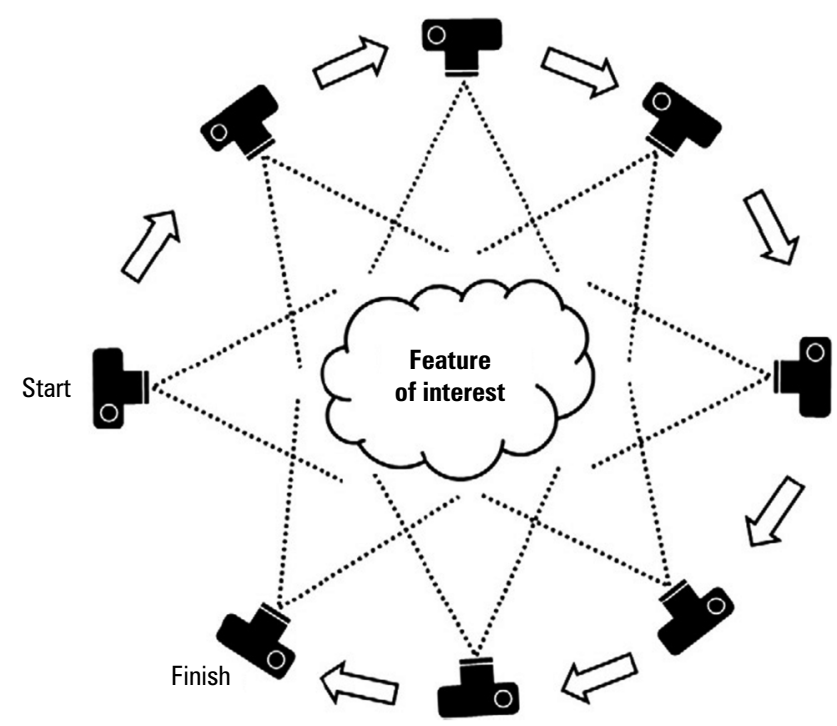

Source: Westoby et al. [2012]

Fig. 1. The Structure from Motion (SfM) approach 
Some of the applications of SfM have included geomorphology [Westoby et al. 2012, 2015, Micheletti et al. 2015, Entwistle and Heritage 2017], forestry and forest monitoring [Panagiotidis et al. 2016, Mlambo et al. 2017, Washburn 2017, Onwudinjo and Smit 2019], 3D terrain modelling [Ishida 2017, Jordan 2017], 3D object reconstruction [Pezzuolo et al. 2018], soil studies [Nouwakpo et al. 2015, Heindel et al. 2018] and in marine biology [Burns et al. 2015]. The emergence of SfM techniques and their incorporation with the classic stereoscopic photogrammetric surveys have revolutionised the production of 3D topographical models. These models are not only appealing but can also contain spatial information, whose quality and accuracy depend on both the survey method used and the applied processing procedures [Caroti et al. 2015, Smith et al. 2016].

Therefore, it is very important to determine the levels of uncertainty inherent in topographic data collection methods, because the quality of topographic datasets influences the accuracy of the data that are derived from them. Using SfM, the accuracy of models can be assessed either by comparing it against a reference model or by measuring the deviation of the control points (measured using classic topographic methods and instrumentation of higher accuracy) identified on the model [Caroti et al. 2015]. Smith et al. [2015] identified three general validation methods for SfM data points: point to point (data points that compare two point clouds directly), point to raster (data points that compare SfM-derived raster such as DSMs with point from topographic data such as from RTK-DGPS or Total Stations), and raster to raster (data points that compare SfM DSMs with equivalent raster-based data products derived from another survey technique such as TLS). However, the choice of validation method is dependent on the available reference data. For example, Mlambo et al. [2017] made comparisons between SfM and airborne LiDAR point clouds and surface models at a test site in Devon, United Kingdom. The results obtained showed a strong correlation between SfM and LiDAR digital surface models $\left(\mathrm{R}^{2}=0.89\right)$. Liu et al. [2018] used an SfM-revised digital surface model (DSM) and multi-view image texture compensation workflow to generate a high-precision True Digital Orthophoto Map (TDOM). The accuracy of the TDOM was evaluated using randomly distributed checkpoints. The horizontal accuracy of the generated TDOM was $36.5 \mathrm{~mm}$, and the vertical accuracy was $32.3 \mathrm{~mm}$. While there is evidence of accuracy assessment of SfM technology in the literature, the advantages offered by ubiquitous Global Navigation Satellite System (GNSS) as a reference source have not been fully explored, particularly the Real Time Kinematic (RTK) approach.

Accordingly, the purpose of this paper is to utilise the RTK-based point-to-point validation technique and two sets of randomly selected ground control points to assess the capability and geometric accuracy of SfM- technology for three-dimensional (3D) terrain mapping over a small study area. This is essential to contribute to the knowledge of applicability as well as supporting sustainable systems. The following section presents a description of the methodology adopted in the study. 


\section{Methods}

The methodology for this study follows the approach of Westoby et al. [2012] shown in Figure 2. The workflow consists of three (3) main stages. However, a software package was used to process the photographs to produce the initial point cloud. The package contains some open-source applications including the Scale Invariant Feature Transform (SIFT) developed by Lowe [2004]; Bundler for bundle adjustment and 3D scene reconstruction [Snavely et al. 2008]; the Clustering View for Multi-View Stereo (CMVS) and the Patch-based Multi-View Stereo (PMVS2) algorithms [Furukawa and Ponce 2007, Furukawa et al. 2010]. These algorithms were executed within the Pix4Dmapper Pro software package used in this study. A detailed description of the SfM workflow is given in Westoby et al. [2012]. The next sections present the discussion on the key elements of the main stages.

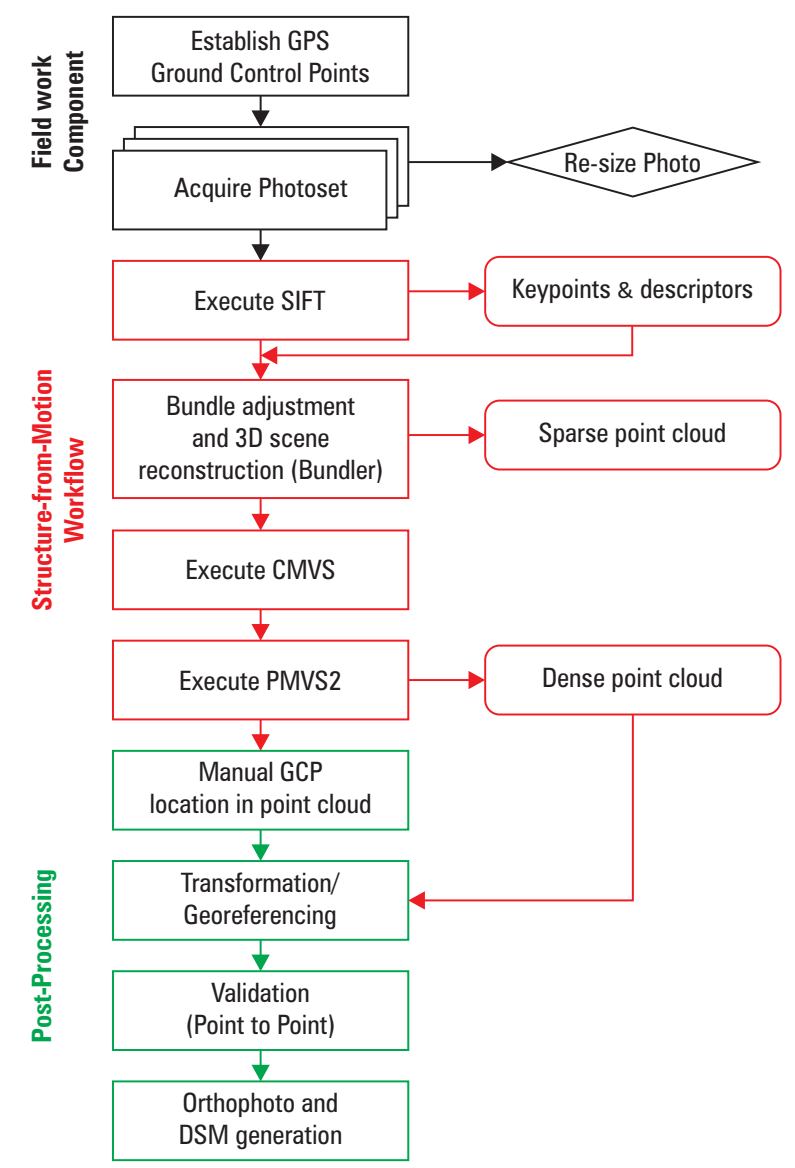

Source: modified from Westoby et al. [2012]

Fig. 2. The Structure-from-Motion workflow 


\subsection{Fieldwork Component}

\subsubsection{Study area}

This study was carried out in a section of the University of Glasgow Garscube Sports Complex near the rugby pitch (between longitudes $4^{\circ} 19^{\prime} 03.64^{\prime \prime} \mathrm{W}$ to $4^{\circ} 19^{\prime} 10.20^{\prime \prime} \mathrm{W}$ and latitudes $55^{\circ} 54^{\prime} 04.97^{\prime \prime} \mathrm{N}$ to $55^{\circ} 54^{\prime} 09.31^{\prime \prime} \mathrm{N}$ ) (Fig. 3). This site was chosen since the Complex is located within the University of Glasgow academic environment, and no special permissions were required to carry out the survey. That is, the ease of accessibility to the Complex and absence of restriction to flying a UAV to acquire data made it a suitable location for this study.

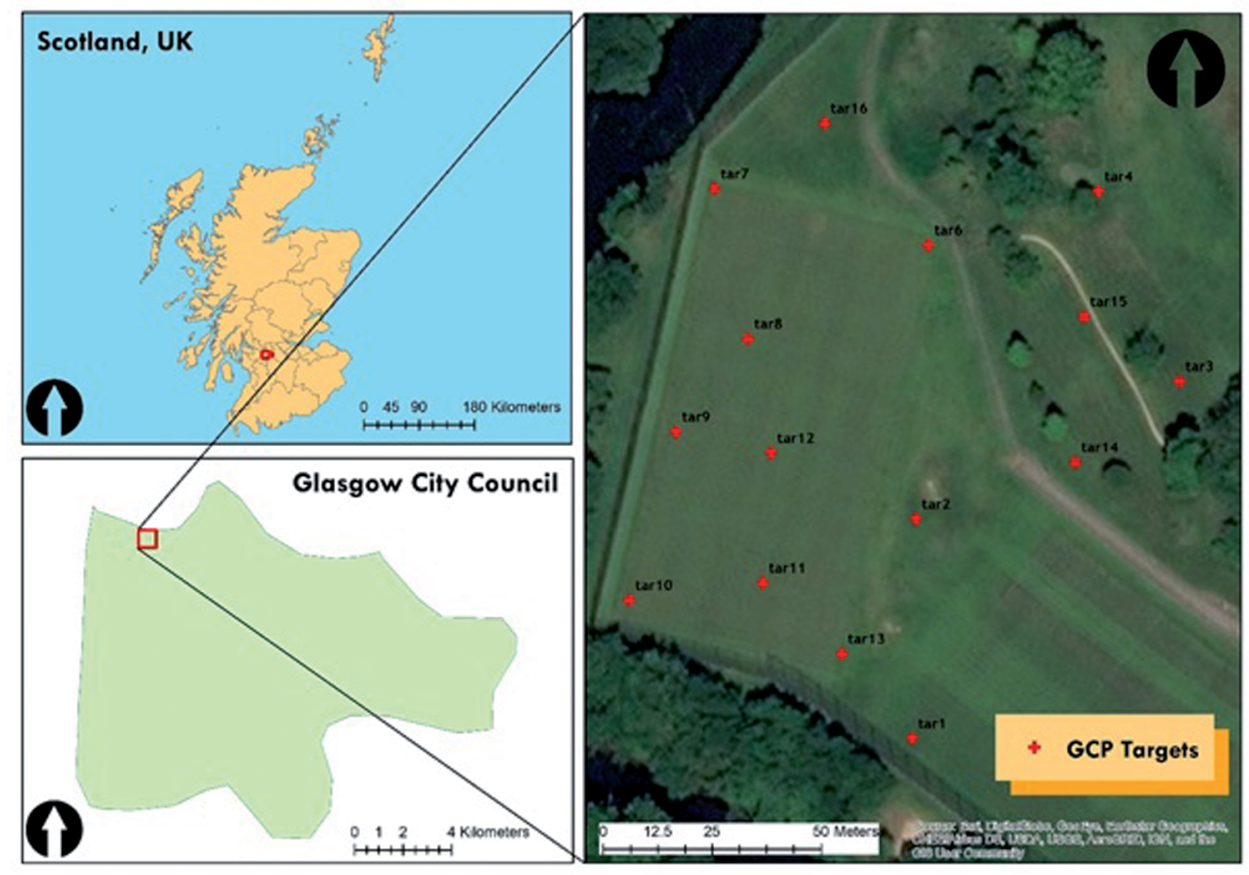

Source: Authors' own study

Fig. 3. Location map of the study area showing the targets points

\subsubsection{Targets marking, position fixing and photo acquisition}

To produce a Digital Surface Model (DSM) from the study, fifteen (15) black square tarpaulins measuring $500 \mathrm{~mm}$ by $500 \mathrm{~mm}$ with a $15 \mathrm{~mm}$ yellow crosshair were used as targets and were evenly spread across the study area (Fig. 3). These targets were coordinated using a Leica network RTK GNSS linked to the GLAS Continuously Operating Reference Station (CORS) via Smartnet. The necessary parameters for the acquisition of reliable data were set according to standards. It has been shown that the incorpora- 
tion of oblique images into the UAV-SfM workflow leads to improved spatial accuracy and precision, including the reduction of systematic errors and data gaps in the final point cloud [Luhmann and Robson 2006, Wackrow and Chandler 2008, Vacca et al. 2017, Nesbit and Hugenholtz 2019]. By integrating oblique images, complete coverage of planar and façade features can be obtained [Gerke 2009, Rau et al. 2015, Nex et al. 2015, Ostrowski 2016, Verykokou and Ioannidis 2018]. Nesbit and Hugenholtz [2019] have also suggested that higher oblique camera angles lead to improvements in accuracy and precision. For this study, the gimbal was set at 70 degrees. Also, the flight path was predefined on the Pix4D Capture software installed on the android device attached to the remote control of the UAV. The home point of the UAV was set from a zero base at one point and the images were captured in sequence according to the grid pattern shown in Figure 4. This was to ensure good coverage and visibility. In the figure, the green line follows the position of the images in time starting from the large blue dot.

The flying height was set at $60 \mathrm{~m}$, this was chosen to ensure a high-resolution data whilst avoiding any interference of the UAV with the surrounding trees. Also, this gives room for an optimum acquisition of UAV data, thereby reducing the processing time in the laboratory. The system was set to capture with a $75 \%$ front overlap and $65 \%$ side overlap with optimised speed and direction automatically set by the Pix4D Capture mobile application. The UAV flew for 5 mins 47 secs covering an area of $153 \mathrm{~m}$ by $129 \mathrm{~m}$. The fieldwork was carried out on the 10th of November 2017.

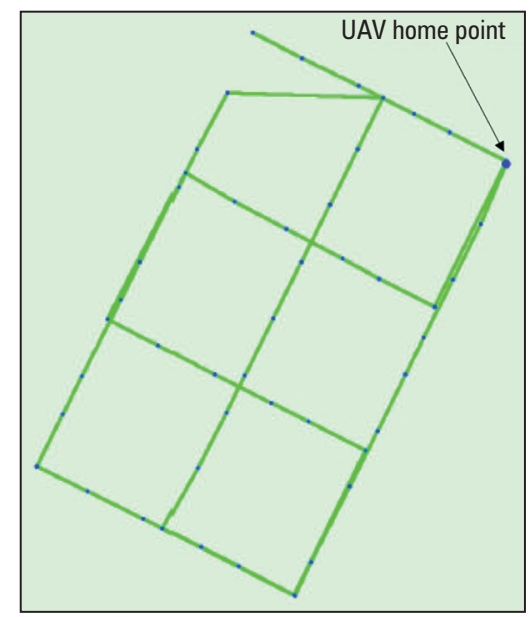

Source: Authors' own study

Fig. 4. UAV flight grid pattern showing the home point

\subsubsection{The UAV system}

A low-cost UAV (DJI Phantom 3 Professional) was used for the aerial data acquisition. The camera lens of the UAV has a focal length of $20 \mathrm{~mm}$ (35 mm equivalent) and 
a sensor of 12.76 megapixels that gives very high-resolution photo shots. Each image has a dimension of $4000 \times 3000$ pixels at a horizontal/vertical resolution of 72 dots per inch (dpi). More details on the camera specifications are provided in DJI [2019]. It also has an in-built Global Positioning System (GPS) with $5 \mathrm{~m}$ accuracy which reduces the amount of time needed to process the photos. This UAV system was chosen for the study because of its low cost and availability in the market. Not only that, but the scale of the work was also another factor considered in the choice of the UAV. The DJI Phantom 3 Professional is shown in Figure 5. The UAV was checked and evaluated prior to embarking on the project. Also, the UAV components were checked to ensure they were in good condition for the task. The final checking and calibration were performed before departure to site.

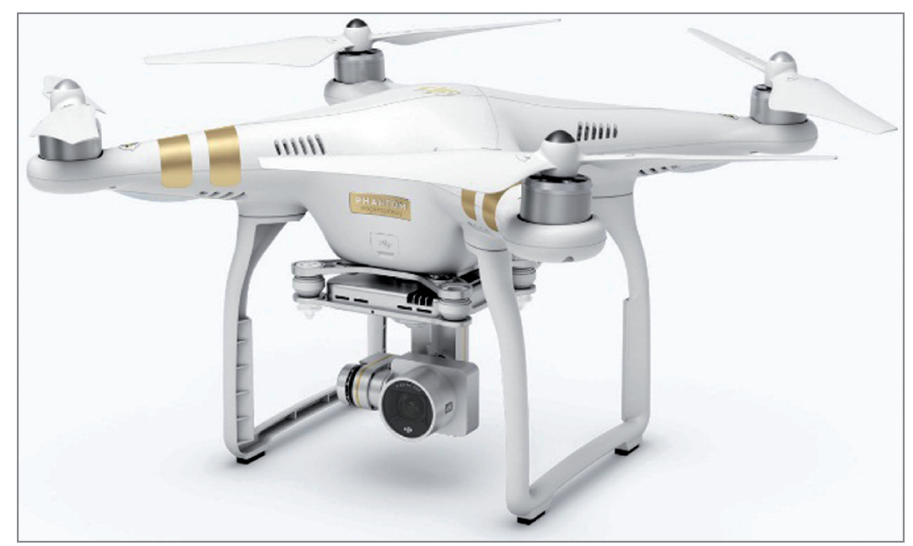

Source: DJI [2019]

Fig. 5. DJI Phantom 3 Professional Unmanned Aerial Vehicle

\subsection{SfM Workflow and Post-processing}

\subsubsection{Data processing}

As a first step, this section presents one of the stages of the workflow shown in Figure 2. The captured data (both from the UAV and the RTK) were downloaded, unzipped, and saved in a directory. The .csv target positions were then imported into ArcMap and plotted against a base map to see their distribution. A project was then set up in the Pix4D software environment. The actual SfM workflow started with the initial processing which handles the image alignment. In the processing options window, the setting "half image size" was selected in order to speed up the processing. The fifteen targets (GCPs) were then imported and matched (georeferenced) using the rayCloud Editor menu. Targets that were not clear were verified by checking the base map in ArcMap as some images contained more than one target. These were then rematched and opti- 
mised, and subsequently a quality report was generated. The generated report revealed that the georeferencing accuracy was within acceptable limits (with mean RMSE of $27 \mathrm{~mm}$ ). After all the targets had been marked, the type was then changed to "Check Point" and afterwards it was rematched and optimised. Checkpoints were used to assess the absolute accuracy of the model. The checkpoint marks were used to estimate its $3 \mathrm{D}$ position as well as potential errors in the clicks. This way, the relative accuracy of the area of the checkpoints may improve. The next step was the point cloud generation. The original resolution of the images could be used but a resampling to a quarter of the original resolution was used in order to reduce the processing time. For each input image, a final point cloud was automatically saved to LiDAR file format (.las) as selected during the initial processing stage. The las format is one of the most common formats for exchanging point clouds. Finally, both the Raster DSM and Orthomosaic were generated and the tiles were merged and saved in a lossless compression format of GeoTiff (.tif) to help preserve the image quality.

\subsubsection{Validation test}

In this study, the validation was performed during the post-processing stage through a comparison of the point cloud data with the $3 \mathrm{D}$ coordinates of the targets. This approach is in line with the point-to-point validation method described by Smith et al. [2015]. For projects with image geolocation, a high number of GCPs help to improve the relative and the absolute accuracy of the model generated [Pix4D Support 2017a]. Thus, the GCPs were used to georeference the model given that a minimum of three GCPs is required to scale, rotate, and locate the model. The GCPs were used to assess the absolute accuracy of the model. This assessment was done in two ways; first, five of the GCPs were changed to checkpoints and later the remaining ten were used, and quality reports were generated at each instance. This was done to evaluate the impact of the number of checkpoints on the root mean square error (RMSE) obtained. To obtain a detailed picture of the magnitude of the errors and the accuracy level in the three-dimensional coordinates of the orthophoto, the following accuracy metrics were computed: standard deviation - SD $(\sigma)$, and RMSE. The RMSE has been widely used by researchers to measure model performance while the SD is a good measure of dispersion. The RMSE indicates the difference between the initial and the computed position of the checkpoints. This RMSE gives an estimate of the absolute accuracy of the model in the area. According to Smith et al. [2015] at a range of $60 \mathrm{~m}$, the expected RMSE for a point-to-point validation is $80 \mathrm{~mm}$. The RMSE and SD of coordinate errors are calculated for the data as follows [Chai and Draxler 2014]:

$$
R M S E=\sqrt{\frac{1}{n} \sum_{i=1}^{n} e_{i}^{2}}
$$

The $\mathrm{SD}$ is given as:

$$
S D=\sqrt{\sum_{i=1}^{n} \frac{\left(e_{i}-\bar{e}\right)^{2}}{n-1}}
$$


Where $e, \bar{e}$ and $n$ denote the coordinate errors (that is, differences between the given coordinates of the targets and the corresponding coordinates on the point cloud), the mean coordinate errors, and the number of targets/sample points respectively.

\section{Results}

\subsection{Target (GCP) Coordinates}

The coordinates of the targets coordinated during the GNSS RTK survey (Network RTK solution) are shown in Table 1. The position and elevation qualities are denoted by RMSE as shown in Table 1 for each point. Typically, Network RTK solutions within the United Kingdom provide instantaneous results (that is, single epoch coordinate solutions) that achieve RMS accuracies of around $10-20 \mathrm{~mm}$ in position (XY) and 20-40 $\mathrm{mm}$ in elevation (Z), with relatively small biases [Edwards et al. 2010]. As shown in Table 1, the position quality obtained ranges from $5.1 \mathrm{~mm}$ at tar 16 to $11.3 \mathrm{~mm}$ at $\operatorname{tar} 7$ while the elevation quality ranges from $9.2 \mathrm{~mm}$ at tar 3 and tar 8 to $18.4 \mathrm{~mm}$ at tar 7 . This result clearly shows a high level of data quality and accuracy in line with Edwards et al. [2010].

Table 1. Coordinates of Targets (GCPs)

\begin{tabular}{|c|c|c|c|c|c|c|}
\hline S/N & Point ID & $\begin{array}{c}\text { Easting } \\
(\mathrm{mE})\end{array}$ & $\begin{array}{c}\text { Northing } \\
(\mathrm{mN})\end{array}$ & $\begin{array}{c}\text { Elevation } \\
(\mathbf{m})\end{array}$ & $\begin{array}{c}\text { Position RMSE } \\
(\mathrm{mm})\end{array}$ & $\begin{array}{c}\text { Elevation RMSE } \\
(\mathrm{mm})\end{array}$ \\
\hline 1 & $\operatorname{tar} 1$ & 255147.6453 & 670015.1591 & 29.2433 & 7.9 & 12.3 \\
\hline 2 & $\operatorname{tar} 2$ & 255140.5468 & 670064.6733 & 29.4649 & 6.9 & 10.6 \\
\hline 3 & $\operatorname{tar} 3$ & 255194.7783 & 670105.2656 & 34.5020 & 5.9 & 9.2 \\
\hline 4 & $\operatorname{tar} 4$ & 255169.6533 & 670145.0903 & 36.3731 & 6.9 & 10.9 \\
\hline 5 & $\operatorname{tar} 6$ & 255133.3817 & 670126.8155 & 28.4989 & 6.3 & 10.2 \\
\hline 6 & $\operatorname{tar} 7$ & 255083.3251 & 670131.7509 & 28.2695 & 11.3 & 18.4 \\
\hline 7 & $\operatorname{tar} 8$ & 255096.2880 & 670099.1783 & 28.7397 & 5.7 & 9.2 \\
\hline 8 & $\operatorname{tar} 9$ & 255083.4714 & 670075.6147 & 28.7643 & 5.5 & 9.7 \\
\hline 9 & $\operatorname{tar} 10$ & 255079.0629 & 670036.0641 & 29.1643 & 9.4 & 15.3 \\
\hline 10 & $\operatorname{tar} 11$ & 255108.4713 & 670044.8036 & 29.1834 & 6.5 & 10.3 \\
\hline 11 & $\operatorname{tar} 12$ & 255105.6348 & 670074.3138 & 28.9596 & 6.8 & 11.0 \\
\hline 12 & $\operatorname{tar} 13$ & 255128.8471 & 670031.6813 & 29.4515 & 63 & 10.0 \\
\hline 13 & $\operatorname{tar} 14$ & 255174.2900 & 670083.2592 & 29.7310 & 5.9 & 9.7 \\
\hline 14 & $\operatorname{tar} 15$ & 255170.9971 & 670116.3769 & 32.8718 & 6.5 & 10.2 \\
\hline 15 & $\operatorname{tar} 16$ & 255105.6405 & 670150.5189 & 28.5001 & 5.1 & 8.5 \\
\hline
\end{tabular}




\subsection{Degree of Image Overlap}

Figure 6 shows the surveyed area and the number of overlapping images at each point. The average Ground Sampling Distance (GSD) obtained between two consecutive pixel centres measured on the ground was $2.63 \mathrm{~cm}$.

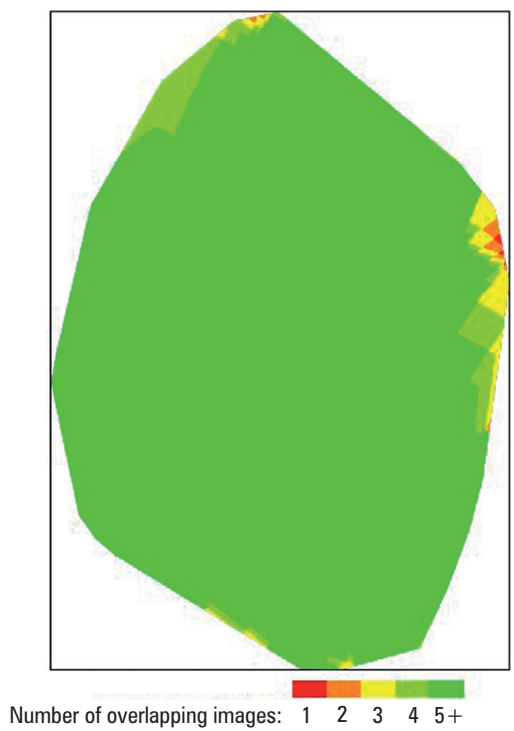

Source: Authors' own study

Fig. 6. Number of overlapping images computed for each pixel of the orthomosaic
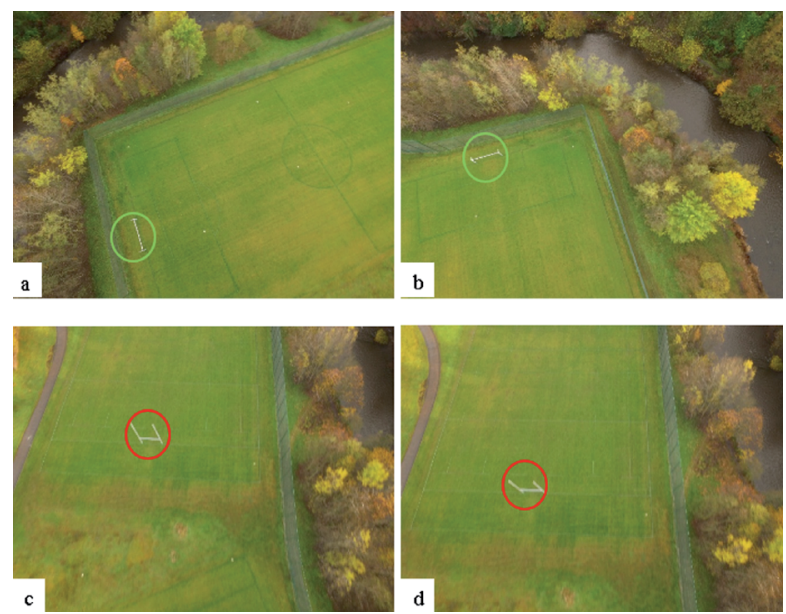

Source: Authors' own study

Fig. 7. A cross-section of images captured during the UAV survey showing different views of the rugby pitch and the adjoining Kelvin River 
The red and yellow areas in Figure 6 indicate areas with low overlap for which poor results may be generated. The green areas indicate an overlap of over 4 images for every point. Since the area is predominantly covered in green, this indicates a good overlap and reliable results.

Figure 7 demonstrates this overlap in a cross-section of images captured during the UAV survey showing different views of the rugby pitch and the adjoining Kelvin River. The green and red circles show regions of overlap between images a and b; and $\mathrm{c}$ and d respectively.

\subsection{D Point Cloud Reconstruction}

The point cloud densification operation achieved 3,386,259 points with an average density of 140.46 points per $\mathrm{m}^{2}$. The $3 \mathrm{D}$ point cloud produced is shown in Figure 8 . The inset $(\mathrm{A})$ shows the reconstruction of trees in the model. This result is very interesting given the level of detail shown in the figure. This implies that better results can be achieved if some of the initial parameters such as the flying height $(60 \mathrm{~m})$ are varied. However, the variation may also be at the expense of storage capability and the processing speed due to the large volume of data that will be involved. However, the principle of economy of accuracy - that is, establishing a balance between cost and accuracy must be followed in every project.

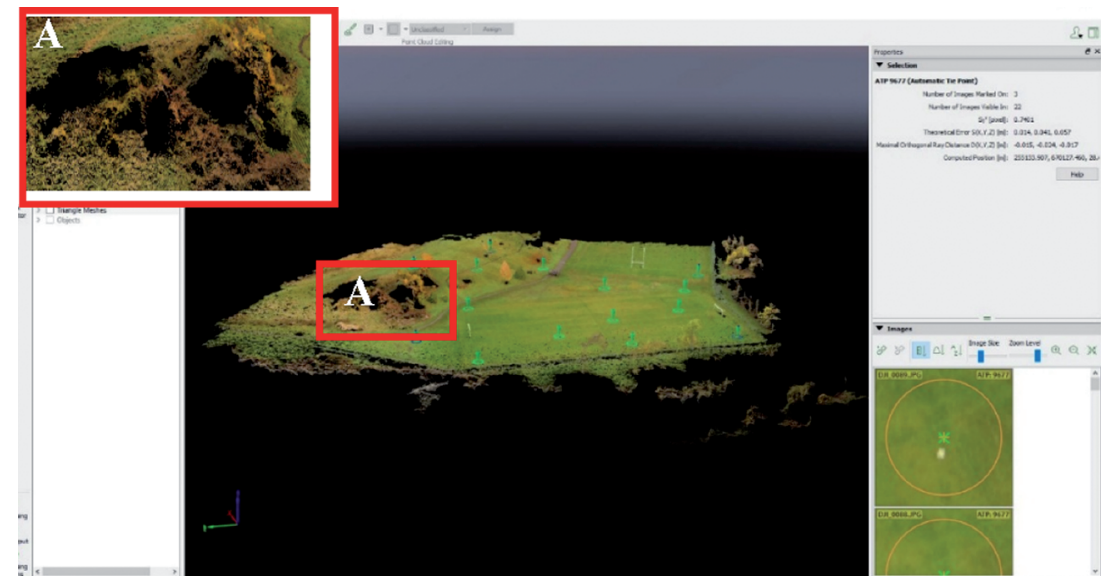

Source: Authors' own study

Fig. 8. Point cloud generated showing the $3 \mathrm{D}$ reconstruction of trees

\subsection{Orthophoto Map and Digital Surface Model}

Figure 9 shows the map produced from the orthophoto that was generated. The full length of the rugby pitch and the playing area is visible. Also visible are a portion of the hockey field, and the trees and shrubs along the banks of the Kelvin River flowing on 
the western edge of the image. Trees are covering an open field northward and eastward of the rugby pitch, a paved road leading into the pitch area and a trail connecting the road. Figure 10 shows the Digital Surface Model (DSM) of the same area. The heights on the DSM range from $25-46 \mathrm{~m}$. The lowest points on the DSM are associated with the open fields while the highest points are in the areas covered by trees and shrubs. The orthophoto was draped on the DSM model in ArcScene to produce a 3D view as shown in Figure 11. The figure shows a good representation of surface features such as the posts on the rugby pitch, and the trees and shrubs on the field. The $3 \mathrm{D}$ model appears very close to reality. Some discontinuity in surface representation can be observed at the edges or outer fringes of the model where there are less dense point clouds. This result revealed the importance of a dense point cloud in obtaining a reliable $3 \mathrm{D}$ terrain model.

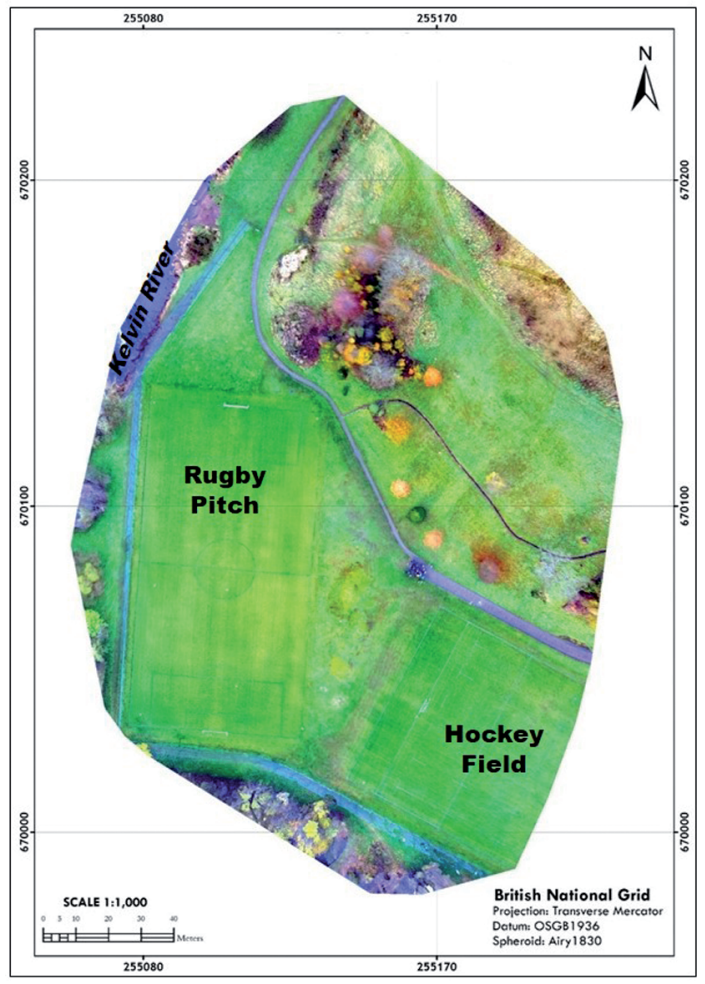

Source: Authors' own study

Fig. 9. Orthophoto map of the study area 


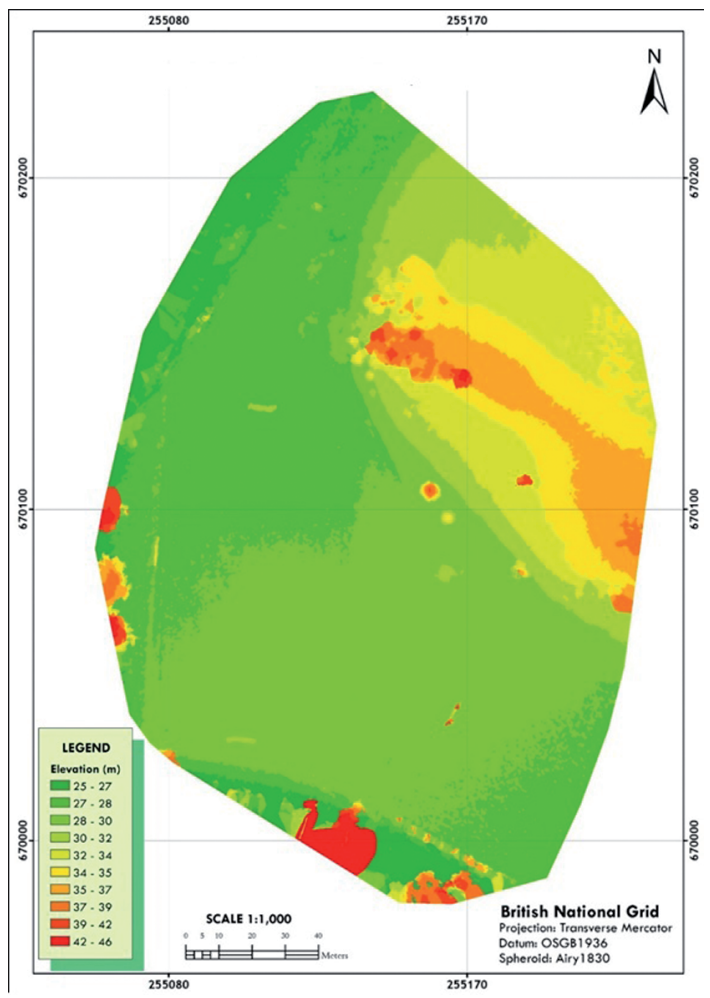

Source: Authors' own study

Fig. 10. Digital surface model (DSM) of the study area

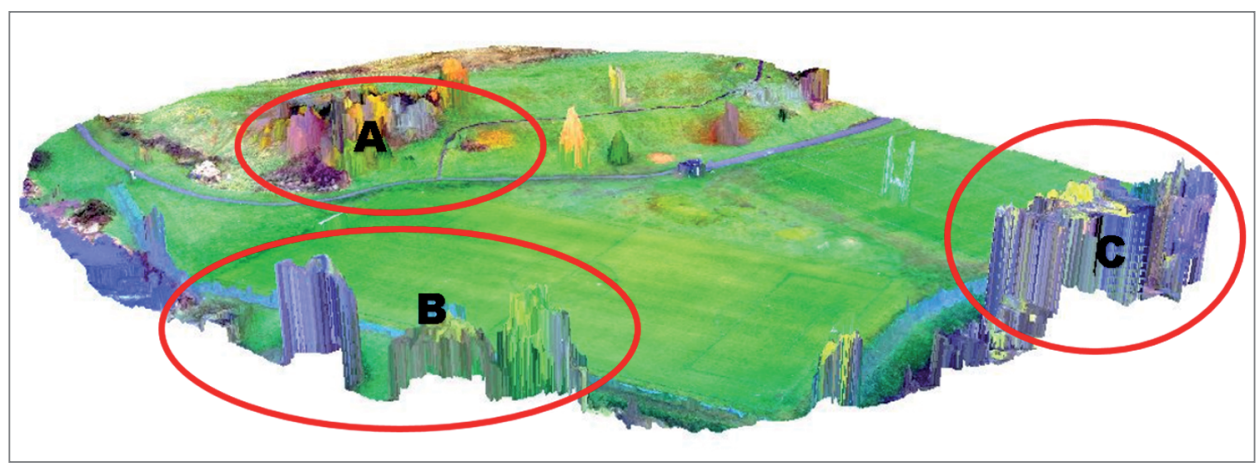

Source: Authors' own study

Fig. 11. Orthophoto draped on the DSM of the study area 


\subsection{Validation of Results}

The validation dataset was based on the RTK-GNSS-derived coordinates of the target cross-hair. Tables 2 and 3 show the point to point geolocation details using ten checkpoints and five checkpoints respectively. The validation with ten checkpoints showed higher accuracy than the validation with 5 checkpoints with lower SDs and RMSEs in the X, Y and Z coordinates as follows: $\mathrm{SD}_{\mathrm{X}}: 20.29 \mathrm{~mm}, \mathrm{SD}_{\mathrm{Y}}: 17.80 \mathrm{~mm}, \mathrm{SD}_{\mathrm{Z}}: 45.74 \mathrm{~mm}$; $\mathrm{RMSE}_{\mathrm{X}}: 20.93 \mathrm{~mm}, \mathrm{RMSE}_{\mathrm{Y}}: 18.48 \mathrm{~mm}, \mathrm{RMSE}_{\mathrm{Z}}: 46.05 \mathrm{~mm}$. Aside the number of checkpoints, careful design and control of the survey are important for obtaining desired accuracies. Still, the number of checkpoints is an important factor/constraint that must be taken into consideration in the application of SfM technique for 3D mapping in line with Ren et al. [2020].

Table 2. Point to Point validation results (using 10 checkpoints)

\begin{tabular}{|l|c|c|c|}
\hline \multicolumn{1}{|c|}{ Accuracy metric } & Error X $(\mathbf{m m})$ & Error Y $(\mathbf{m m})$ & Error Z (mm) \\
\hline Mean & -5.13 & 4.94 & 5.34 \\
\hline SD & 20.29 & 17.80 & 45.74 \\
\hline RMSE & 20.93 & 18.48 & 46.05 \\
\hline
\end{tabular}

Table 3. Point to Point validation results (using 5 checkpoints)

\begin{tabular}{|l|c|c|c|}
\hline \multicolumn{1}{|c|}{ Accuracy metric } & Error X $(\mathrm{mm})$ & Error $\mathrm{Y}(\mathrm{mm})$ & Error Z (mm) \\
\hline Mean & -11.88 & -4.89 & -39.19 \\
\hline SD & 44.34 & 21.73 & 64.25 \\
\hline RMSE & 45.90 & 22.27 & 75.26 \\
\hline
\end{tabular}

\section{Discussion}

Image acquisition for SfM is aimed at capturing the scene of interest from as many different viewpoints as possible, hence the name multiview stereo [Smith et al. 2015]. The result presented in section 3.1 shows that there was an adequate overlap of images within the study area. However, there were areas - particularly some edges of the model generated - that did not have an adequate overlap which is a result of the flight path. The flight path is meant to cover the area/feature of interest so that there is an adequate overlap as this has a huge impact on the quality of the results generated [Harwin et al. 2012]. In the areas with vegetation, the point cloud data generated had some black areas as shown in Figure 8 which suggests that the coverage in those areas was not adequate and this was reflected in the $3 \mathrm{D}$ model created using the DSM. The areas with those gaps and less overlap were generalised as shown in Figure 11 (A, B and C). As a result of the complex geometry of trees (with numerous branches and leaves), extract- 
ing characteristic key points in the image was difficult. To obtain the best result, it is recommended to increase the flying height and overlap as noted by Smith et al. [2016]. This will make it easier to detect visual similarities between the overlapping images. The best result is usually obtained at a GSD of about $10 \mathrm{~cm} /$ pixel. This is in agreement with Pix4D Support [2017b]. The model produced was validated using the Point-toPoint method as discussed in Section 2.2.2. The results obtained when ten checkpoints were used fell within the expected range. However, when five checkpoints were used a slightly higher value of RMSE was obtained. This suggests that better accuracy could be achieved with more GCPs and checkpoints.

\section{Conclusions}

This study examined the application of Structure-from-Motion (SfM) photogrammetry for 3D terrain mapping. Essentially, this study utilised the GNSS RTK technique as a novel approach to understanding the achievable accuracy of the technology given some relevant factors such as the flying height and ground control points. It employed the point-to-point method of validation for its assessment. The validation tests suggest that higher numbers of checkpoints, evenly distributed within the study area, could increase the accuracy of the model. However, further analysis would be required not only to test the influence of the number of ground control points on the accuracy, but also their configuration. The flying height of $60 \mathrm{~m}$ used in this study was found not very effective in extracting key points necessary to reconstruct the complex geometry of trees but was adequate for orthophoto and digital surface model generation. To obtain good accuracy in the model, it is imperative to have many viewpoints and an adequate number of GCPs evenly distributed within the area of interest. Generally, it is to be noted that the quality of the data captured is dependent on the methodology adopted and should be taken into consideration. Also, further studies are required to arrive at a consensus on the use of particular imaging angles when capturing oblique (off-nadir) images in SfM. In conclusion, the study has shown that SfM technique is cost-effective and can be used to produce high-resolution three-dimensional topographic data that is useful for geoscience applications. Therefore, it is recommended for further study to continue to explore its potential.

\section{Acknowledgements}

The authors are grateful to the School of Geographical and Earth Sciences, University of Glasgow, where the fieldwork for this paper was conducted as part of coursework in the Geospatial and Mapping Sciences programme. A special thanks and appreciation to Pix4D Support who made their help files freely available and accessible.

This research received no specific grant from any funding agency in the public, commercial, or not-for-profit sectors. 


\section{References}

Burns J.H.R., Delparte D., Gates R.D., Takabayashi M. 2015. Integrating structure-from-motion photogrammetry with geospatial software as a novel technique for quantifying $3 \mathrm{D}$ ecological characteristics of coral reefs. Peer J 3:e1077. DOI: 10.7717/peerj.1077

Caroti G., Zaragoza I.M.E., Piemonte A. 2015. Accuracy assessment in structure from motion 3D reconstruction from UAV-born images: The influence of the data processing methods. The International Archives of Photogrammetry, Remote Sensing and Spatial Information Sciences, 40(1), 103-109.

Chai T., Draxler R.R. 2014. Root mean square error (RMSE) or mean absolute error (MAE)? Arguments against avoiding RMSE in the literature. Geoscientific Model Development, 7, 1247-1250. https://doi.org/10.5194/gmd-7-1247-2014.

Dietrich J.T. 2014. Applications of Structure-from-Motion Photogrammetry to Fluvial Geomorphology. PhD Thesis, University of Oregon, USA.

DJI 2019. DJI Phantom 3 Professional. https://www.dji.com/phantom-3-pro [accessed: 4.10.2019].

Edwards E.J., Clarke P.J., Penna N.T., Goebell S. 2010. An examination of network RTK GPS services in Great Britain. Survey Review, 42(316), 107-121.

Entwistle N.S., Heritage G. 2017. An evaluation DEM accuracy acquired using a small unmanned aerial vehicle across a riverine environment. International Journal of New Technology and Research, 3(17), 43-48.

Furukawa Y., Ponce J. 2007. Accurate, dense, and robust multi-view stereopsis. In: Proceedings, IEEE Conference on Computer Vision and Pattern Recognition 2007, 1-8.

Furukawa Y., Curless B., Seitz M., Szeliski R. 2010. Clustering view for multi-view stereo. In: Proceedings, IEEE Conference on Computer Vision and Pattern Recognition 2010, 1434-1441.

Gerke M. 2009. Dense Matching in High Resolution Oblique Airborne Images. ISPRS Int. Arch. Photogramm. Remote Sens. Spat. Inf. Sci., XXXVIII, 77-82.

Harwin S., Lucieer A. 2012. Assessing the accuracy of georeferenced point clouds produced via multi-view stereopsis from unmanned aerial vehicle (UAV) imagery. Remote Sensing, 4(6), 1573-1599. https://doi.org/10.3390/rs4061573

Heindel R.C., Chipman J.W., Dietrich J.T., Virginia R.A. 2018. Quantifying rates of soil deflation with Structure-from-Motion photogrammetry in west Greenland. Arctic, Antarctic, and Alpine Research, 50(1), S100012, 14pps. doi: 10.1080/15230430.2017.1415852

Ishida K. 2017. Investigating the accuracy of 3D models created using SfM. 34th International Symposium on Automation and Robotics in Construction, 834-839.

Jordan J.H. 2017. Modeling Ozark Caves with Structure-from-Motion Photogrammetry: An Assessment of Stand-Alone Photogrammetry for 3-Dimensional Cave Survey. Theses and Dissertations, 2406 (2017). University of Arkansas. http://scholarworks.uark.edu/etd/2406.

Liu Y., Zheng X., Ai G., Zhang Y., Zuo Y. 2018. Generating a High-Precision True Digital Orthophoto Map Based on UAV Images. In: ISPRS International Journal of Geoinformation, 7 (333), 15pps. doi:10.3390/ijgi7090333.

Lowe D. 2004. Distinctive image features from scale-invariant keypoints. International Journal of Computer Vision, 60, 91-110.

Luhmann T., Robson S. 2006. Close Range Photogrammetry Principles, Techniques and Applications. Whittles, Dunbeath, UK.

Micheletti N., Chandler J.H., Lane S.N. 2015. Structure from motion (SFM) photogrammetry. In: Geomorphological Techniques (online edition), eds. L.E. Clarke, J.M. Nield. British Society for Geomorphology, London, Chap. 2, Sec. 2.2. 
Mlambo R., Woodhouse I.H., Gerard F., Anderson K. 2017. Structure from Motion (SfM) Photogrammetry with Drone Data: A Low Cost Method for Monitoring Greenhouse Gas Emissions from Forests in Developing Countries. Forests, 8(68), 20pps. doi:10.3390/f8030068.

Nesbit P., Hugenholtz C. 2019. Enhancing UAV-SfM 3D Model Accuracy in High-Relief Landscapes by Incorporating Oblique Images. Remote Sensing, 11(3), 239. MDPI AG. http:// dx.doi.org/10.3390/rs11030239.

Nex F., Gerke M., Remondino F., Przybilla H.-J., Bäumker M., Zurhorst A. 2015. Benchmark for Multi-Platform Photogrammetry. ISPRS Ann. Photogramm. Remote Sens. Spat. Inf. Sci., II-3/W4,135-142.

Nilosek D., Walvoord D.J., Salvaggio C. 2014. Assessing geoaccuracy of structure from motion point clouds from long range image collections. Optical Engineering, 53(11), 113112. doi: 10.1117/1.OE.53.11.113112

Nouwakpo S.K., Weltz M.A., Mcgwire K. 2015. Assessing the performance of structure-frommotion photogrammetry and terrestrial LiDAR for reconstructing soil surface microtopography of naturally vegetated plots. Earth Surface Processes and Landforms, 41(3), 308-322. doi: 10.1002 /esp.3787.

Onwudinjo K.C., Smit J.L. 2019. Evaluating the Performance of Multi-Rotor Unmanned Aerial Vehicle - Structure from Motion (UAV-SfM) Imagery in Assessing Simple and Complex Forest Structures: Comparison to Airborne and Terrestrial Laser Scanning. 6th EBE Research Expo, University of Cape Town. doi: 10.13140/RG.2.2.24115.48164

Ostwald A.M., Hurtado J.M. 2017. 3D Models from Structure-from-Motion Photogrammetry using Mars Science Laboratory Images: Methods and Implications. Lunar and Planetary Science, XLVIII (2017). 2pps.

Ostrowski W. 2016. Accuracy of measurements in oblique aerial images for urban environment. Int. Arch. Photogramm. Remote Sens. Spat. Inf. Sci. ISPRS Arch., 42, 79-85.

Panagiotidis D., Surový P., Kuželka K. 2016. Accuracy of Structure from Motion models in comparison with terrestrial laser scanner for the analysis of DBH and height influence on error behaviour. Journal of Forest Science, 62(8), 357-365. doi: 10.17221/92/2015-JFS

Pezzuolo A., Giora D., Sartori L., Guercini S. 2018. Automated 3D Reconstruction of Rural Buildings from Structure-from-Motion (SfM) Photogrammetry Approach, 23-25. doi: 10.22616/ERDev2018.17. N060

PIX4D Support. 2017a. Ground Sampling Distance, GSD. https://support.pix4d.com/hc/enus/articles/202559809-Ground-Sampling-Distance-GSD-\#gsc.tab=0. (2017a) [accessed: 30.11.2017].

PIX4D Support. 2017b. Using GCPs. https://support.pix4d.com/hc/en-us/articles/202558699Using-GCPs\#gsc.tab=0. (2017b) [accessed: 30.11.2017].

Raoult V., Reid-Anderson S., Ferri A., Williamson J.E. 2017. How Reliable is Structure from Motion (SfM) over Time and between Observers? A Case Study Using Coral Reef Bommies. Remote Sensing, 9(740), 15pps. doi:10.3390/rs9070740.

Rau J.Y., Jhan J.P., Hsu Y.C. 2015. Analysis of oblique aerial images for land cover and point cloud classification in an urban environment. IEEE Trans. Geosci. Remote Sens., 53, 1304-1319.

Ren H., Zhao Y., Xiao W., Wang X., Sui T. 2020. An Improved Ground Control Point Configuration for Digital Surface Model Construction in a Coal Waste Dump Using an Unmanned Aerial Vehicle System. Remote Sensing, 12(10), 1623. MDPI AG. http://dx.doi.org/10.3390/ rs12101623

Smith M.W., Vericat D. 2015. From experimental plots to experimental landscapes: topography, erosion and deposition in sub-humid badlands from structure-from-motion photogrammetry. Earth Surface Processes and Landforms, 40(12), 1656-1671. 
Smith M.W., Carrivick J.L., Quincey D.J. 2016. Structure from motion photogrammetry in physical geography. Progress in Physical Geography, 40(2), 247-275.

Snavely N. 2008. Scene reconstruction and visualization from Internet photo collections, unpublished $\mathrm{PhD}$ thesis. University of Washington, USA.

Snavely N., Seitz S.N., Szeliski R. 2008. Modeling the world from internet photo collections. International Journal of Computer Vision, 80, 189-210.

Vacca G., Dessi A., Sacco A. 2017. The Use of Nadir and Oblique UAV Images for Building Knowledge. ISPRS Int. J. Geo-Inf., 6, 393: doi:10.3390/ijgi6120393www.mdpi.com/journal/ ijgi

Verykokou S., Ioannidis C. 2018. Oblique aerial images: A review focusing on georeferencing procedures. Int. J. Remote Sens., 39, 3452-3496.

Wackrow R., Chandler J.H. 2008. A convergent image configuration for DEM extraction that minimises the systematic effects caused by an inaccurate lens model. Photogramm. Rec., 23, 6-18.

Washburn M. 2017. Digital Terrain Model Generation using Structure from Motion: Influence of Canopy Closure and Interpolation Method on Accuracy. M.Sc. Thesis, Texas State University, USA.

Westoby M.J., Brasington J., Glasser N.F., Hambrey M.J., Reynolds J.M. 2012. Structure-fromMotion photogrammetry: A low-cost, effective tool for geoscience applications. Geomorphology, 179, 300-314.

Westoby M.J., Dunning S.A., Woodward J., Hein A.S., Marrero S.M., Winter K., Sugden D.E. 2015. Instruments and methods - Sedimentological characterization of Antarctic moraines using UAVs and Structure-from-Motion photogrammetry. Journal of Glaciology, 61(230). doi: 10.3189/2015JoG15J086.

Wróżyński R., Pyszny K., Sojka M., Przybyła C., Murat-Błażejewska S. 2017. Ground volume assessment using Structure from Motion photogrammetry with a smartphone and a compact camera. Open Geosciences, 9, 281-294.

\footnotetext{
MSc/MA Chima Jude Iheaturu

Imo State University, Nigeria

Department of Surveying and Geoinformatics

e-mail: chima.geomaven@gmail.com

ORCID: 0000-0003-0472-9715

PhD Emmanuel Gbenga Ayodele

University of Lagos, Nigeria

Department of Surveying and Geoinformatics

e-mail: eayodele@unilag.edu.ng

ORCID: 0000-0003-2684-2276

MSc/MA Chukwuma John Okolie

University of Lagos, Nigeria

Department of Surveying and Geoinformatics

e-mail: cokolie@unilag.edu.ng

ORCID: 0000-0003-4542-7051
} 